\title{
A Meta-Analysis of Vocabulary Learning Strategies of EFL Learners
}

\author{
Batoul Nematollahi ${ }^{1}$, Fatemeh Behjat ${ }^{1} \&$ Ali Asghar Kargar $^{1}$ \\ ${ }^{1}$ Department of English, Abadeh Branch, Islamic Azad University, Abadeh, Iran \\ Correspondence: Fatemeh Behjat, Department of English, Abadeh Branch, Islamic Azad University, Abadeh, Iran. \\ E-mail: fbehjat@iauabadeh.ac.ir
}

Received: December 21, $2016 \quad$ Accepted: April 1, 2017 Online Published: April 3, 2017
$\begin{aligned} & \text { doi: 10.5539/elt.v10n5p1 } \\ & \text { URL: http://doi.org/10.5539/elt.v10n5p1 }\end{aligned}$

\begin{abstract}
Vocabulary learning is one of the crucial matters in second language learning. There is a vast body of research in this field which has been done by famous researchers around the world, but still there is no specific solution for extending lexical knowledge in the best way. Therefore, we have conducted a meta-analysis on a body of 30 research projects to investigate the usefulness of different strategies of vocabulary learning. The results showed that the strategies which are used by students are as follows in order: determination, cognitive, memory, meta-cognitive, and social strategies. Besides, it seems that guessing from context and using the dictionary are among the strategies which are most favored by successful students. In addition, the relationship between context, treatment, and methodology by vocabulary learning strategy were studied. It was clear that learners of different contexts would prefer different strategies, and teachers used specific strategies according to their syllabus. For further research, it is suggested to select a larger body of studies. It is advised to make teachers aware of the importance of choosing an appropriate strategy of vocabulary learning for language learners to pave the way of improving lexical knowledge for them.
\end{abstract}

Keywords: Meta-analysis, learning strategies, vocabulary learning

\section{Introduction}

Vocabulary is a center part of language ability and produces the foundation for learning how well scholars speak, read, write, and listen. It is without a doubt that vocabulary is considered as a key to all the language skills, since it covers all lexical items learners need to know in order to meet their numerous educational and general needs. A person with a limited vocabulary will never be able to speak, write, read or understand a language effectively (Mutalib, 2014).

Knowledge of vocabulary can only be obtained via the teaching approaches that address to different learning forms (Browne, 2014). Without having plans for obtaining distinct vocabulary items, scholars usually gain less than their possible regarding academic progress. Nation (2001) believed that a significant number of vocabulary could be obtained via the assistant of vocabulary learning approaches, and the plans are proved beneficial for learners with various language stages (Nation, 2006). Using vocabulary learning approaches makes learners able to control their learning and take their own learning responsibility.

There are different definitions for strategies proposed by famous scholars. Brown (2007) describes strategies as, "those specific attacks that we make on a given problem that vary considerably within each individual" (Brown, 1983). Chamot (2005) believes that strategies are procedures which facilitate learning task and they are conscious and goal driven (Chamot, 1994). Naveh et al. (2011), stated that "a vocabulary strategy is special instructional tool and way of going about directly or explicitly as well as the independent word learning skills required to learn words independently" (Dansereau, 1988). There are also other definitions for strategies proposed by Oxford (1990), Schmith (1997), and Nation (2001). These researchers not only defined strategies, but also suggested classifications for learning strategies (Schmitt, 1997).

Since 1960s, there have been different taxonomies for learning strategies (Nation, 2006). In this regard, various classifications of vocabulary learning strategies exist, among which Schmitt's (1997) was considered the most useful one for this research. He divided the strategies to "discovery" and "consolidation" strategies. The former included determination and social strategies; the latter, social, memory, cognitive, and metacognitive strategies (Schmitt, 1997).

Generally, vocabulary can be taught and learnt in different ways, each of which with its own merits and demerits. 
Teachers use several ways of instructing lexical items and students choose a divergent range of strategies, according to their learning context, age, gender and level of proficiency, culture, needs, and other factors. The result of numerous studies in this field, shows that all of the strategies could be helpful in vocabulary learning, when they are applied properly. Those who are aware of the strategies and use them when necessary, have been proved to be better language learners.

In this study, the author's purpose is to make generalization of vocabulary learning strategies for EFL students. Taking this into point, the author compares instructional methods usefulness regarding two important factors: achievement outcomes and effective conditions for EFL students. Thus, meta-analysis metric was applied to compare the results of each experiment or quasi-experiment study.

\section{Review of Related Literature}

\subsection{Classification of Vocabulary Learning Strategies}

As mentioned before, there are different taxonomies among which Schmitt's was used in present survey. According to Oxford (1990) there are direct and indirect strategies, each of which are divided to different groups. Schmitt took social, memory and meta-cognitive approaches established by Oxford, and invented a new category that is discovery approaches (Schmitt, 1997). This category is used to found out the meaning of new words without asking for someone else's help. Therefore, learners try to understand the meanings utilizing the context, structural knowledge of language, and the reference materials (Zimmerman, 2001). The other main group of strategies in this classification is consolidation, in which a word is consolidated when it is encountered. He divides these two groups to five sub-categories as follows:

1) Determination strategies facilitate gaining knowledge of a new lexical item. Learners may be able to discern the new words' part of speech, which can help in guessing process. There are different kinds of methods regarding this kind of strategy. Some examples include: analyzing part of speech, analyzing affixes and roots, checking for a L1 cognate, analyzing pictures or gestures, guessing from textual context, using a bilingual or monolingual dictionary, using word lists or flash cards (Schmitt, 1997). Results of different studies have revealed that different learners prefer different strategies and after applying it in their learning process, they have been able to promote their knowledge.

2) Social strategies is categorized both under discovery and consolidation strategies. When the learner tries to find out the meaning by asking others, and receives a L1 translation, synonym, paraphrasing, a sentence containing the new item, or any kind of mixing these ways, then he/she would discover the meaning. Besides, as a consolidation strategy, it promotes active information processing. Using words in a social context would motivate the learners and prepare them for group work out of the class. Because of teachers' minimized role in this method, students would be able to use and manipulate the language in the class (Schmitt, 1997). Examples of this kind of strategy contains: asking teacher for an L1 translation, paraphrasing or giving the synonym of the new word, a sentence including the new word, asking classmates for the meaning, discover new meaning through group work activity, study and practice meaning in a group, teacher's checking the learners' flash cards or word lists for accuracy, and link via native speakers (Ahmed, 1989).

3) Memory or mnemonic strategies mean linking the students' learning of new words to mental processing by relating what is already known, to the new words. This involves a wide range of techniques, as follows: studying words with a graphic description of its meaning, drawing words purposes, relating words to a personal event, connecting the words via its coordinates, relating the word to its antonyms and synonyms, utilizing semantic maps, utilizing scales for gradable adjectives, peg scheme, Loci approach, grouping words to examine them, grouping words spatially on a page, employing new words in a sentence, asserting words together in a story line, studying spelling of a word, studying the sound of a word, saying a word aloud while studying, imaging word form, underlining initial letter of a word, configuration, using keyword plan, paraphrasing the meaning, parts of speech, using cognates, learning the words of an idiom together, utilizing physical action, and using semantic characteristic grids (Schmitt, 1997).

4) Cognitive strategies are defined as those which assist a person in achieving a particular goal (Rubin, 1987). Cognitive strategies enable the second language learner to "manipulate the language material in direct ways, e.g., through reasoning, analysis, note-taking, summarizing, synthesizing, outlining, reorganizing information to develop stronger schemas (knowledge structures), practicing in naturalistic settings, and practicing structures and sounds formally" (Oxford, 2002). This group includes using mechanical means, such as vocabulary notebooks, to study new words.

5) Metacognitive approaches manage, direct and control the learning manner. These sorts of policies include 
thinking regarding learning manner, planning, monitoring and assessing learning (Rahimi, 2012). Metacognition is a kind of cognition and it is about high level thinking process, involving conscious control over learning process. Advanced, successful learners are aware of their learning and they apply various strategies when they face a new word in different situations. Using English language media (songs, movies, newscasts, etc.), testing oneself with word tests, using spaced word practice, skipping or passing the new words, and continue to study words over time, are different kinds of meta-cognitive strategies proposed by Schmitt (1997).

\subsection{Meta-analysis}

A meta-analysis is a kind of statistical method that includes mixing and interpreting the consequences of several different investigations dedicated to a particular issue. This method permits researchers to get a better look at overall aims and recognize possible links that might exist (Cherry, 2012). As a meta-analysis mix several smaller units to a much larger data, researchers can sometimes recognize trends that could not be seen in smaller-scale investigations.

A meta-analysis can be especially helpful if some factors have been linked to a special event and can usually be used to narrow on the most important contributing parts. Furthermore, meta-analysis can be employed when there are weak or contradictory results, found by smaller studies.

Meta-analysis means statistical methods for contrasting and combining results from multiple experiments or quasi experiments in the hope of achieving a final result of all the effect sizes. In statistics, an effect size is a quantitative measure of the strength of each experiment. In this study, this measure is the difference between student outcomes as treatment group and control group respectively, which is divided by the final standard deviations (Toyama, 2010).

The meta-analytic method has five basic stages (Glass, 1976). Head, it is formulating the problem; determining what issues the meta-analyst hopes to respond and what sorts of evidence to test. The second stage involves assembling the data, searching for all investigations on the problem by every possible means. Third, the data should be assessed; deciding which of the collected data is accurate and useful and eliminating considerations that do not meet these criteria. The fourth stage is utilizing statistical techniques like possibilities and effect sizes, to reconcile and aggregate different subjects. Ultimately, it is time to present the findings and report the resulting "analysis of analyses" to the wider research community, providing details, data and methods used.

\subsection{Empirical Studies on Students' Vocabulary Learning Strategies}

Vocabulary knowledge is pivotal in the second and foreign language acquisition (Afshar, 2010). A review of literature shows that vocabulary instruction varies for each studies. There is a vast body of research regarding vocabulary. Different articles have been published about the various methods of vocabulary learning. Findings of the studies are rich and diverse relating to the aim of the research. Therefore some, of them will be mentioned in this part of our study.

According to Sarani and Shirzaei (2016), undergraduate and post graduate EFL students use different vocabulary learning strategies. After examining 150 male and female learners at BA and MA university levels whose ages ranged from 18 to 42 , they found out that there was a significant difference between highly-motivated learners and low-motivated learners' use of such strategies. Even the participants' gender and their motivation were related (Anderson, 1980).

Alyami (2016), asked seventy-five undergraduate students to report the strategies they used. The result showed that the least frequently used strategies were those that require higher order thinking skills, such as, "organizing words by meaning group", and the most frequently used dimension was "reasons for not taking strategies", while the least frequently used dimension was "ways of organizing notes taken" (Nyikos, 2007).

Memory strategies help learners to abet their memory. They are aimed at improving encoding efficiently by associating between new and earlier information which already exist in mind.

In a study conducted by Fatima and Pathan (2016), 180 undergraduate students answered 45 close-ended items on four broad vocabulary learning strategies. It was revealed that cognitive regulation strategy, and activation strategy emerged as the most influential source of learning new English words. Furtheremore, there were no statically significant differences found in practiving vocabulary learning strategies between undergraduates of the two universities (Uzun, 2013).

Improving lexical knowledge is even useful for learners of other majors. University students often have difficulty learning technical terms of their specific books. Tahriri and Fallah (2013) investigated the use of strategies for learning vocabulary among twenty engineering students. The results of the descriptive statistics 
showed that these students were medium strategy users who reported memory strategy as the most frequently used strategy and meta-cognitive strategy as the least frequently used strategy. As for the relationship between the participants' proficiency level and their choice of vocabulary learning strategies, the results of the Pearson correlation showed not statistically significant relationship in either of the strategy categories (Alamdari, 2010).

Nacera (2010) investigated the relationship between language learning strategies and vocabulary size. The results showed that students use direct strategies that influence information processing. Besides, meta-cognitive strategies are the mostly used strategies. In addition, students who have larger vocabulary size use strategies which need more time and will lead to effective learning (Nacera, 2010).

In this research, the author is aimed at invetigating whether or not a meta-analysis on effective vocabulary strategies show which one leads to a better vocabulary learning for EFL students, direct or indirect strategy. On the other hand, this research is trying to figure out the relationship between the effectiveness of vocabulary learning strategies and different learning contexts, treatments, and research methods based on a meta-analysis.

\section{Method}

In this meta-analysis, the researcher included those studies that involved treatment on vocabulary learning strategies, where control and experimental groups were involved, and, the effect of vocabulary learning strategy use was a dependent variable.

The data collected in different studies were taken into a serious consideration. As it was difficult to directly compare different studies with uneven data available and group sizes, we performed a meta-analysis and measured the effect of some major strategies on the vocabulary learning. Moderator variables such as age were measured on nominal scale.

In these studies, multiple tests have been conducted to measure the influence of an intervention on EFL learners' vocabulary learning. SPSS helped to measure means and standard deviations with the representative effect size.

Regarding the fact that most studies included effect sizes, we only considered the reported numbers. To have one representative effect size for each study, the effect sizes were averaged.

Meta-analysis means a large collection of analysis results for the purpose of integrating the findings (Glass, 1976). Taking this point into consideration, a report of previous research using statistical methodology and analysis was provided. Using statistical methods and providing more objective and exact results than a narrative review are basic features of a meta-analysis.

To analyze the effect sizes, a software package of comprehensive meta-analysis, developed by BioStat (www.meta-analysis.com) was used. Through using this instrument, the type of data to be provided, and the method of analysis were determined as we had to decide which data we needed and how we should analyze them.

Effect sizes were different because the subjects and interventions of the study were different. The purpose was to calculate the mean of the distribution of effect sizes, that is, the effect of all strategies on learning vocabulary.

To this end, we used means and standard deviations as the major descriptive statistics applied in the resent study. To answer the second research question, the data were interpreted qualitatively.

In order to decrease bias and increase validity of reviewing different instructional methods, we applied a meta-analysis. Through such a technique, we synthesized some research results regarding the instruction of vocabulary to English learners. Effect size is used by meta-analysis as a usual metric to compare results obtaining from experimental or quasi-experimental studies.

This study has a descriptive and qualitative design because it describes and measures the effectiveness of a treatment. In this case, the purpose of the study is to see the most influential strategies on vocabulary learning strategies for EFL students.

For the studies included in this meta-analysis, both test and quasi-experimental studies were available for composition. Investigations involved had to use either a pretest-posttest control group plan, posttest control via randomization, or pretest-posttest within-subject plan.

\section{Results}

This part of research is intended to present and analyze the data obtained for the purpose of the study. It is divided into three major sections, results, detailed description of research questions and discussion. The first section tabulates and analyzes the data using SPSS (Statistical Package for Social Science, Version 19) software for statistical operations of quantitative data while the second section shows the extent to which research 
questions can be answered, and it assesses the validity of the research questions. It is done through the quantitative analyses of the elicited data. To realize vocabulary learning methods preferred by the participants, descriptive statistics of means and standard deviations for five categories were selected.

\subsection{The First Research Question}

Does a meta-analysis on effective vocabulary strategies show which one leads to a better vocabulary learning for EFL students, direct or indirect strategy?

In order to answer this question, descriptive statistics was carried out for the five most frequent vocabulary learning strategies. Table 1 presents it as follows:

Table 1. Descriptive statistics for the five most frequent vocabulary learning strategies

\begin{tabular}{lc}
\hline Strategy & M \\
SD & 31.76 \\
\hline Determination & 26.95 \\
5.42 & \\
Cognitive & 25.5 \\
4.16 & \\
Memory & 13.92 \\
4.28 & \\
Meta-cognitive & 10.66 \\
3.51 & \\
Social & \\
3.73 & \\
\hline
\end{tabular}

According to this table, there are 5 strategies including determination, cognitive, memory, meta-cognitive and social, which basically affect vocabulary learning. The means of these strategies are $31.76,26.95,25.5,13.92$, and 10.66 , respectively. Their standard deviations are 5.42, 4.16, 4.28, 3.51, and 3.73, respectively. As can be seen in Table 1, there are some differences between the five strategies group in terms of mean and standard deviation.

The mean of the first strategy which is determination was the maximum, indicating that this strategy is direct strategy and is more than other strategies. In general, by considering the mean table, it can be concluded that cognitive, memory strategies are at the moderate level because the mean of these two strategies almost the same as each other.

According to the above table, the last two strategies which are meta-cognitive and social, have lowest level of mean. But, the mean of memory strategy is higher than social strategy. Therefore, it is at the low moderate level, and social is at the minimum level, indicates that this strategy is not actively used by the participants. Therefore, it is the indirect strategy. This process can be shown in Figure 1. 


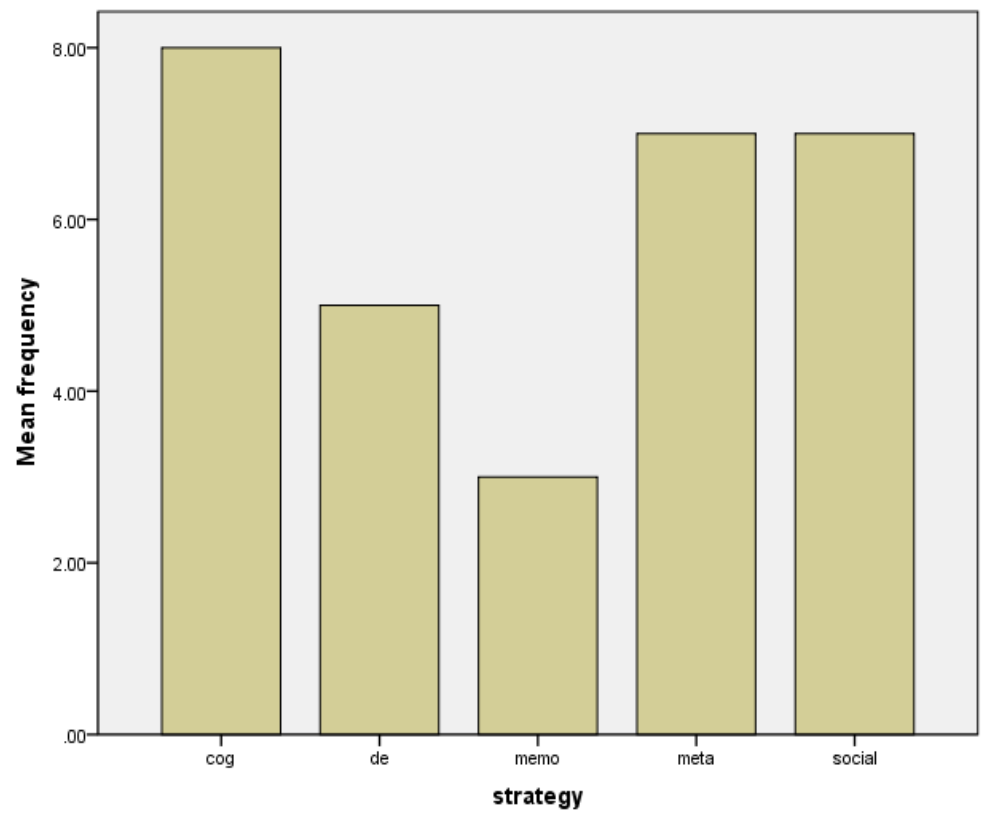

Figure 1. Descriptive statistics for five most frequent vocabulary learning strategies

In the present meta-analysis, the effect sizes were mentioned or calculated using mean and standard deviations. Figure 1 shows that which strategy is direct (most effective) or indirect (least effective) respectively. It can be stated that as a direct strategy leads to a better vocabulary learning, determination strategy is most effective. Generally, there were some strategies commonly-used by all participants in different studies, which were categorized as determination, cognitive, memory, meta-cognitive, and social strategies. The related means and standard deviations were obtained. Table 2 shows the results.

Table 2. The most and least-reported vocabulary learning strategies

\begin{tabular}{llll}
\hline Description & Category & Mean & SD \\
\hline Guessing from textual context & Determination & 4.21 & 1.00 \\
Using a monolingual dictionary & Determination & 3.98 & 0.93 \\
Repeating the word verbally & Cognitive & 3.93 & 0.98 \\
Analyzing the parts of speech & Determination & 3.84 & 0.97 \\
Studying the sound of the word & Memory & 3.80 & 1.03 \\
Keeping a vocabulary notebook & Cognitive & 3.78 & 0.93 \\
Using English labels for objects & Cognitive & 1.98 & 1.00 \\
Asking the teacher for making sentence & Social & 1.72 & 1.02 \\
Asking the teacher for L1 translation & Social & 1.56 & 0.99 \\
Inferencing the new word meanings & Meta-cognitive & 1.83 & 0.8 \\
Using flash cards & Meta-cognitive & 1.80 & 0.83 \\
Memorizing words initial letter & Memory & 1.99 & 0.93 \\
\hline
\end{tabular}

Table 2 indicated that Guessing from textual context has the highest mean and standard deviation of 4.21 and 1.00 , and it belongs to determination strategy. So, it is at the highest level among strategies. The second highest mean $(\mathrm{M}=3.98)$ is related to determination strategy consulting a monolingual dictionary, and its standard deviation is 0.93 . The third strategy is repeating the word verbally of cognitive strategy, with the mean of 3.93 and standard deviation of 0.98 . The forth one is analyzing the parts of speech. It is also determination strategy, 
and its mean and standard deviations are 3.84 and 0.97 . The fifth is studying the pronunciation of the word. It involves memory strategy, and its mean and standard deviation are 3.80 and 1.03 . The sixth category is keeping $a$ vocabulary notebook, a cognitive strategy with 3.78 and 0.93 as its mean and standard deviation. Using English labels for objects is the seventh category of cognitive strategy and the mean of 1.98 and standard deviation of 1.00. The eighth category involves asking the teacher for making a sentence, a social strategy, with the mean and standard deviation of 1.72 and 1.02, respectively. The ninth item is related to asking the teacher for L1 translation, which is a social strategy. Its mean is 1.56 and its standard deviation is 0.99 . Another description is Skipping or passing the new word meanings which is the tenth item. It contains Meta-cognitive strategy, with mean of 1.83 and standard deviation 0.8. The eleventh description refers to Using flash cards with meta-cognitive strategy with 1.80 and 0.83 as its mean and standard deviation. The last and twelfth description is memorizing words initial letter. Its strategy, is memory and its mean and standard deviation are 1.99 and 0.93 .

This table shows that strategies which have high means included the first six descriptions such as "Guessing from textual context", "Using a monolingual dictionary", "Repeating the word verbally", "Analyzing the parts of speech", "Studying the pronunciation of the word", and "Keeping a vocabulary notebook" and the second six descriptions like "Using English labels for objects", "Asking the teacher for making sentence", "Asking the teacher for L1 translation", "Inferencing the new word meanings", "Using flash cards" and "Memorizing words initial letter" have low mean and standard deviation. This again implies what exactly direct and indirect strategies EFL learners use in learning new vocabulary items. Yet, it specifies that direct strategies are basically used more for vocabulary learning.

\subsection{Second Research Question}

Is there any relationship between the effectiveness of vocabulary learning strategies and different learning contexts, treatments, and research methods based on a meta-analysis?

In order to answer the second research question, the studies were reconsidered in terms of the relationship between the intended variables and vocabulary learning strategies. This was done qualitatively.

The relationship between treatment and vocabulary learning has been shown in some studies (O'Malley \& Chamot, 1990) as the use of various treatments is based on accepted cultures in a country. Teacher-centered content was reported in Iran while a relationship was observed between group work in the class vocabulary learning in other countries (Zohrabi, 2012). This emphasized a direct relationship in the effectiveness of different treatments and learners' vocabulary learning. The learners' successful uses of strategies for learning words were based on their attitudes and motivation (Alemi, 2011).

The relationship between vocabulary learning strategies and research methods were in some studies (Cohen \& Aphek, 1981). Best chances of input could be observed in contexts containing learning activities, characteristics of learners, language tasks, and learners' style preferences, learner strategies, use of different materials, task purpose, task in various levels of strategies and strategies of different vocabulary learning. All factors worked together within a particular learning context.

Considering the thirty studies under the investigation, there are 12 studies, the contexts of which are Iranian. Based on descriptive statistics and independent sample t-test, With regard to "asking my teacher for an L1 translation", Amirian and Heshmatifar (2013) reported 'asking my teacher for L1 translation' as a social strategy was used rarely by EFL university students (Amirian, 2013).

\section{Discussion}

The results of this study showed that determination strategy is the most favored and used strategy. The second type is cognitive strategies; the third type is memory strategies; the fourth one is meta-cognitive strategies, and the fifth one was social strategies. Guessing from context with the mean of 4.21, and dictionary use with the mean of 3.98 were the most preferred strategies, and they were ranked as the highest selected strategies.

The result of the first question showed that the meta-analysis on EFL learners' vocabulary learning strategies shows direct strategies lead to a better vocabulary learning, and the result of second question indicated that, there is a relationship between the effectiveness of vocabulary learning strategies and different learning contexts, treatments, and research methods according to the meta-analysis.

The other result was that many students were not familiar with certain learning strategies such as group work activity. In conclusion, this highlights the role of strategy training in the classrooms, just as has been shown by Nation (2001). He claims it that it enhances the basic knowledge of learning as it creates an opportunity for being autonomous in learning vocabulary and it is direct strategy. 
This study was a meta-analysis of a body research on EFL learners' vocabulary learning strategies. It is widely accepted that knowing the rationale behind learning a second language vocabulary is the basic point in studying it. This research was also aimed at finding the relationship between factors such as context, treatment, research method and vocabulary learning, and strategy use. So, it is indirect strategy.

\section{Conclusion}

In this research, a meta-analysis of thirty research projects on the effectiveness of vocabulary learning strategies for EFL students was used. These strategies included determination, cognitive, memory, meta-cognitive, and social. They are related to different ways learners choose to learn vocabulary items at different levels, for different purposes and in different contexts. In order to show the findings, descriptive statistics, basically mean and standard deviations were used. In this research, all the effect sizes were either reported or calculated as high. In all 30 studies, there were two groups of experimental and control group. The experimental groups received instruction in vocabulary strategies and control group had traditional instruction on vocabulary items. In some studies, the relationship between some independent variables such as content and treatment with vocabulary learning were also investigated.

Most people need to learn a foreign or second language, and it is one of the challenging processes that majority of people will face during their lives. English is now a language of information exchange between people of different countries. Every language has a large index of vocabulary items. Vocabulary is a main factor of language proficiency and provides the basis for understanding how well learners listen, speak, read, and write. In order to acquire new vocabulary, there are different strategies, without which learners often achieve less than their potential in terms of academic success. Using different vocabulary items are related to the variety of contexts and communicative activities. All in all, a clear representing of vocabulary learning strategies can provide a useful roadmap for those students in need of it.

Based on the results, it can be observed in the five vocabulary learning strategies of Schemitt's taxonomy were observed in all studies.

Finally, the findings of the present study, as cited before, indicated that there are some differences between the five strategies group in terms of mean and standard deviation. This research showed which strategy was direct or indirect respectively. It was indicated that delimitation strategy was direct because it is more than other strategies, and it can be concluded cognitive, memory strategies were not as much used, and the use of social strategies as an indirect strategy was the lowest.

There were 12 descriptions for five strategies. The first six techniques involved guessing from textual context, using a monolingual dictionary, repeating the word verbally, analyzing the parts of speech, studying the sound of the word, and keeping a vocabulary notebook. The second six techniques in learning included using English labels for objects, asking the teacher for making sentence, asking the teacher for L1 translation, skipping or passing the new wording, using flash cards and memorizing words initial letter.

As for the pedagogical implications, teachers can inform the students to have conscious knowledge of learning strategies. Teachers can help learners to get best and appropriate strategies that increase their level of proficiency. Additionally, it seems that a teacher at higher levels of education should be familiar with all varied strategies of vocabulary learning to make all students familiar with all related varied strategies.

One of the limitations may be that, this research was conducted on the studies collected by the researcher. Unavailability and prohibitive costs prevented the researcher from accessing some other relevant studies. If a larger sample group had been used, perhaps the results would have been even more significant.

Another point to be considered is that, analyzing the effect of treatment on choosing a special strategy was not easy. There were different obstacles in this regard which should be more studied.

Limited research experience of a meta-analysis might be thought of as another limitation of this study. Better interpretation skills on the issues would enhance this study.

Despite of the above mentioned limitations, the results of this study indicated some directions for further studies. Future research should be in such a way that it may appeal to a large number of EFL learners and consider the development for better vocabulary learning strategies into account. Future research should attempt to study meta-analysis of this method with students in various levels of education and with different levels of English proficiency. It is to suggest that further studies on the use of meta-analysis to evaluate vocabulary learning strategies be carried out. 


\section{References}

Afshar, S., Ketabi, K., \& Tavakoli, S. (2010). An investigation into good and poor Iranian EFL majors' vocabulary learning strategies. TELL, 3(10), 45-74.

Ahmed, M. O. (1989). Vocabulary learning strategies. In P. Meara, (Ed.) Beyond words (pp. 3-14). London: British Association for Applied Linguistics, in association with Centre for Information on Language Teaching and Research.

Alamdari, Z., S. (2010). The relationship between vocabulary learning strategies employed by university level English language learners and their success. Unpublished master"s dissertation. Hacettepe University, Ankara.

Alemi, M., \& Tayebi, A. R. (2011). The Influence of incidental andi vocabulary acquisition and vocabulary strategy use on learning L2 vocabularies. Journal of Language Teaching and Research, 2(1), 81-98. https://doi.org/10.4304/jltr.2.1.81-98

Amirian, M. R., \& Heshmatifar, Z. (2013). The study of vocabulary learning strategies of Iranian EFL university students, Hakim Sabzevari university, Iran. International Journal of Research Studies in Educational Technology, 2(1). 35-44.

Anderson, J. (1980). The lexical difficulties of English medical discourse for Egyptian studies. English for specific purposes (oregon state university), 37(4).

Brown, F.G. (1983). Principles of Educational and Psychological Testing. New York: Holt.

Browne, C. (2014). A new general service list: the better mousetrap we've been.

Chamot, A. U., \& Rubin, J. (1994). Comments on Janie Rees-Miller's “A critical appraisal of learner training: Theoretical bases and teaching implications. Two readers react... TESOL Quarterly, 28(4), 771-776. https://doi.org/10.2307/3587559

Dansereau, D. F. (1988). Cooperative learning strategies. In C. E. Weinstein, E. T. Goetz, \& P. A. Alexander, (Eds.), Learning and Study Strategies: Issues in Assessment, Instruction, and Evaluation. New York: Academic Press. https://doi.org/10.1016/B978-0-12-742460-6.50013-X

Glass, G. V. (1976). Primary, secondary, and meta-analysis of research. Educational Researcher, 5, 3-8. https://doi.org/10.3102/0013189X005010003

Mutalib, A. H., Abdul Kadir, R. A., \& Robani, R. B. (2014). Vocabulary learning strategies among Malaysian TEVT students in German-Malaysian institute (GMI). Procedia- social and behavioral sciences, 123, 361-368. https://doi.org/10.1016/j.sbspro.2014.01.1434

Nacera, A. (2010). Languages learning strategies and the vocabulary size. Procedia social and behavioral sciences, 2, 4021-4025. https://doi.org/10.1016/j.sbspro.2010.03.634

Nation, I. (2006). How large a vocabulary is needed for reading and listening. The Canadian Modern Language Review, 59-82. https://doi.org/10.3138/cmlr.63.1.59

Nyikos, M., \& Fan, M. (2007). A review of vocabulary learning strategies: Focus on language proficiency and learner voice. In A. D. Cohen, \& E. Macaro. (Eds.), Language Learner Strategies (pp. 251-274). Oxford: Oxford Univer.

Oxford, D. (2002). Language learning strategies in a nutshell: Updated ESL suggestions. In J. C. Richards, \& A. W. Renadya (Eds.), Methodology in languages teaching, An anthology of current practice. Cambridge: Cambridge university press. https://doi.org/10.1017/CBO9780511667190.018

Rahimi, M., \& Katal, M. (2012). The role of metacognitive listening strategies awareness and podcast-use readiness in using podcasting for learning English as a foreign language. Computers in Human Behavior, 28, 1153-1161. https://doi.org/10.1016/j.chb.2012.01.025

Rubin, J. (1987). Learner strategies: theoretical assumptions, research history and typology. In A. Wenden, \& J. Rubin (Eds.), Learner Strategies in Language Learning. New York: Prentice Hall.

Schmitt, N., \& McCarthy, M. (1997). Vocabulary: description, acquisition and pedagogy. Cambridge: Cambredge University Press.

Toyama, K. (2010). Can technology end poverty? Boston review. Available online at www.bostonreview.net/BR35.6/toyama.php. 
Uzun, L. (2013). Promoting vocabulary learning through vocabulary notebooks: Teaching and learning strategies and gender. Journal of Academic Language \& Learning, A1- A13.

Zimmerman, B. J., \& Schunk, D. H. (2001). Self-regulated learning and academic achievement. Mahwah, NJ: Erlbaum.

Zohrabi, M., Torabi, M. A., \& Privash, B. P. (2012). Teacher-centered and/or student-centered learning: English Language in Iran. English Language and Literature Studies, 2(3), 18-30. https://doi.org/10.5539/ells.v2n3p18

\section{Copyrights}

Copyright for this article is retained by the author(s), with first publication rights granted to the journal.

This is an open-access article distributed under the terms and conditions of the Creative Commons Attribution license (http://creativecommons.org/licenses/by/4.0/). 